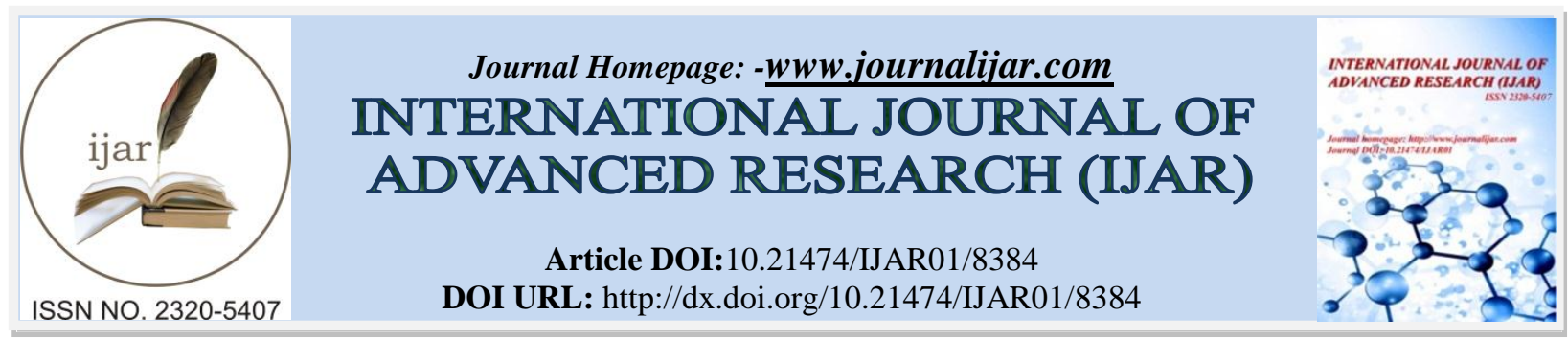

RESEARCH ARTICLE

\title{
EFFECT OF ACTIVITY BASED COSTING (ABC) ON THE PRODUCTIVITY OF MANUFACTURING COMPANY.
}

Sunday A. Effiong and Ambrose E. Akpan.

Department of Accounting, Faculty of Management Sciences, University of Calabar, PMB 1115, Calabar, Cross River State.

\section{Manuscript Info}

Manuscript History

Received: 12 November 2018

Final Accepted: 14 December 2018

Published: January 2019

Key words:-

Activity Based Costing, Traditional Costing, Cost drivers, Overhead Costing, Production efficiency, Productivity, Manufacturing companies.

\section{Abstract}

The aim of this study was to evaluate the degree of influence of Activity-Based-Costing (ABC) on manufacturing productivity. Traditional cost accounting method, which allocates overhead costs on the basis of one driver, that is, overhead absorption base (e.g. direct labor hour, machine hour, etc.) is inaccurate and misleading as this method often allocates too much cost to a product, based on the overhead absorption base, and not enough to another. To address this problem, activities- based - cost accounting method was developed to provide a means of creating a more accurate representation of how activities performed in the creation of a product or service actually impact costs. The study made used of survey descriptive research design method where data were collected through questionnaire. The collected data were analyzed using the ordinary least square regression method. The results showed that $\mathrm{ABC}$ method is significantly and positively related to production process efficiency. Conclusively, rather than allocating overhead on the basis of one variable, such as direct labor, $\mathrm{ABC}$ effectively uses multiple cost drivers to present a more accurate foundation for overhead costs allocation. It was recommended that a clear understanding of $\mathrm{ABC}$ method and its effective implementation will help gain competitive advantages and achieve higher level of productivity performance of manufacturing companies.

Copy Right, IJAR, 2018,. All rights reserved.

\section{Introduction:-}

These days global competition has forced manufacturing companies and organizations to become more flexible, integrated and highly automated in order to increase their productivity at reduced costs. But it is impossible to sustain competitiveness without an accurate cost calculation mechanism (Ozbayrak, Akgun\&Turker, 2004). As proposed by Cooper and Kaplan, (2008), as an alternative method to traditional cost accounting methods, Activity Based Costing ( $\mathrm{ABC}$ ) assigns costs to activities using multiple cost drivers, and then allocates costs to products based on each product's use of these activities (Kim, Park, \& Kaiser, 2007; Gunasekaran\&Sarhadi, 2008). Using multiple activities as cost drivers reduces the risk of distortion and provides accurate cost information (Kim, Park, \& Kaiser, 2007).

Corresponding Author:-Sunday A. Effiong.

Address:-Department of Accounting, Faculty of Management Sciences ,University of Calabar, PMB 1115, Calabar, Cross River State. 
In an Activity Based Costing (ABC) system, the total cost of a product equals the cost of the raw materials plus the sum of the cost of all value adding activities to produce it (Gunasekaran\&Sarhadi, 2008). In other words, the ABC method models the usage of the organization's resources by the activities performed and links the cost of these activities to outputs, (Ben-Arieh, \&Qian, 2013). Each product requires a number of activities such as design, engineering, purchasing, production and quality control. Each activity consumes resources of different categories such as the working time of the manager. Cost drivers are often measures of the activities performed such as number of units produced, labor hours, hours of equipment time, number of orders received, etc.

In traditional cost accounting system, direct materials and labor are the only costs that can be traced directly to the product. By using the ABC system, activities can be classified as value-added and non-value-added activities. In order to improve the performance of the system, non-value-added activities can be eliminated. Despite the advantages of providing accurate costs, it requires additional effort and expense in obtaining the information needed for the analysis (Lewis, 2015). However, a proper design tool can help to reduce the time used for modeling and overcome the difficulties present in designing a cost model.

Johnson and Kaplan (2007) brought revolution into the history of the management accounting. The then management accounting systems failed to provide relevant information for product costing and performance evaluation in the time of 'rapid technological changes', 'fierce competition', and 'information processing revolution'. The pre-war cost accounting systems were designed to meet the financial reporting and tax planning needs. They failed to provide information for managerial decision-making and control purposes. Drucker (1992) argued that accounting systems should provide answers about the businesses, markets, customers, and environment to 'inform literate' manager. Thus, the role of a management accountant expanded in multiple dimensions. They were not just to collect the cost information as accurately as possible but also analyze the utility of the cost information for taking vital managerial decisions. This new paradigm of management accounting called for certain additional skills of the management accountants. Anastas (2011) discussed the changes required in the skill set of the management accountants in view of the "Project Millennium: Customers \& Future Markets...Looking Ahead to 2012". The newfound utility of cost accounting led to a churning of the whole cost accounting system, its methodology and even its philosophy in the mid 1980s. The most prominent that emerged out of the whole brain storming process was activity-based cost management system. This system was claimed to have the ability of providing accurate cost information while removing distortions in product/service pricing and customer profitability analysis in a complex manufacturing environment (Cooper \& Kaplan 2008).

Tradition accounting systems generally allocate all manufacturing overhead costs as a function of the number of products being provided by the organization. This unit-based costing (UBC) works well in fairly simple settings. Activity Based Costing (ABC) method instead identifies specific activities that incur costs and uses these "cost drivers" to allocate shared costs. For example, purchasing department's costs can be an overhead item. The specific cost driver used to allocate such costs to an individual product might be the number of purchase orders associated with components for that product. Activity Based Costing (ABC) is especially relevant to manufacturing because it allows companies to determine much more accurately the actual cost of making a product in today's manufacturing environment.

The environment around companies changes continuously. In the present era of global competition and evolving technologies, consumers are demanding lower prices, superior quality products/services and aggressive pricing. Furthermore, increasing levels of global competition are complement by shortened product life cycles. More frequency in product development, greater product diversity, increased automation and direct labor costs have decreased resulting in facilitating costs being increased, (Bjornenak\& Olson, 2009). These changes have increasingly influenced managers who must seek new strategies, re-organization new techniques or innovations and more complex cost management systems in order to create continuous improvement and profit growth. Increasing the value for activities process can increase the competitive advantage to ensure the survival of firm in the world of high uncertainty and competitiveness (Beheshti, 2004; Drury \&Tayles, 2005) especially, increasing indirect costs. Having more diverse product lines and more complex products call for more sophisticated cost management system in order to be accurate and gain creditability of cost information which is necessary for corporation to seize the information adequately and to support the decision making effectiveness (Drury \&Tayles, 2000). The sophisticated cost management system helps to better the management of resources and increase competitive advantage in terms of costs, quality and firm performance (Kaplan \& Cooper, 2008). Thus, cost information accuracy and creditability are the primary weapons that ensure corporate survival in any competitive environment. 
The core idea of $\mathrm{ABC}$ is the production of goods/services which are generated through activities which consume resources. The cost of a unit of product is to focus on the activity necessary to produce such products/services.

Costs of resources are traced to various products/services based on various activities. Previous researches reveal that a bigger number of companies use $\mathrm{ABC}$ method in providing timely, accurate and understandable and accessible cost information (Adams, 1996) and solution to overcome the distortion in the product costs by traditional costing system (Kaplan, 2004). ABC solves the problems of traditional cost management systems (Cooper \& Kaplan, 2008) which is claimed by large number of researchers to be able to provide more accurately allocated costs than the traditional cost systems (Ben-Arieh\&Qian, 2013).

Activity based costing (ABC) implementation is a strategic cost management decision. According to Snead (2012) and Turner (2013), a continuous gap exists between the capabilities provided by this new cost management system and the extent to which this system is accepted and used by companies. David and Alson (2003) found that the use of a new system is voluntary; individuals not accepting the system may resist it. When the system is mandatory, a lack of user acceptance can lead to high error rates, deliberate sabotage and increased personnel turnover. Burke and Huff (2005) observed that a lack of user acceptance may negate the potential benefits of a new system like ABC resulting in less than effective use of organizational resources. As a result, many practitioners and academicians consider user acceptance to be a primary indicant of successful implementation. Unfortunately many companies still do not realize the importance of $\mathrm{ABC}$ as a strategic cost management philosophy. Some companies have however shown considerable interest in the implementation of $\mathrm{ABC}$. Activity Based costing implementation needs a change in the attitudes of both top and middle managers, and staff with a clear understanding of the move to an $\mathrm{ABC}$ approach.

Shortly after the World War II, a "manage-by-the numbers" culture rapidly developed and almost universally captured the hearts and minds of business leaders (Goldratt, 2013). The center-piece of this movement was standard cost accounting systems that provided the "numbers" for a wide variety of decisions. Corporate managers generally assumed that their standard cost systems generated information that accurately reflected the costs of producing goods and services. But in general, the cost information grossly distorted reality. Hiding behind a cloak of precision and generally accepted accounting principles primarily designed to satisfy external reporting requirements, fatally flawed standard cost systems and their supporting performance measured routinely triggered poor decisions and dysfunctional organization behaviours.

In the 1980s, standard costing systems first came under attack when Goldratt (2013) argued that "cost accounting is the number one energy of productivity." A classic work by Johnson and Kaplan (2007) described the shortcomings and effects of traditional costing systems in great detail. Managers soon began to realize that standard cost data distorts product cost and product margin estimates, causes poor product mix and product pricing decisions, resulting in poor resource allocation, and leads to improper outsourcing decisions. It also became evident that traditional absorption (standard costing; unit-based costing) costing encourages unneeded production in order to capture overhead in inventory rather than in cost of goods sold. This not only contributes to poor resource allocation, but leads to higher costs, longer production lead times and lower quality. Interestingly, as the fallacies of standard cost systems became widely understood, most managers simply looked for a way to upgrade their traditional cost systems. Activity Based Costing $(\mathrm{ABC})$ projects often fail because project managers ignore the cardinal rule: It is better to be approximately correct than to be precisely inaccurate. When it comes to $\mathrm{ABC}$, close enough is not only good enough; close enough is often the secret to success. When implementing $\mathrm{ABC}$, manufacturing companies can stumble in three areas: use of average cost rates, use of overly detailed information, and failure to connect information to action. In the use of average cost rates, some manufacturing companies use commercial software for profitability analysis that requires cost-per-unit-of-each rates for various outputs or events. These rates are retrieved external to the software. As a shortcut, some manufacturing companies rely on published unit-cost-rate averages to multiply against their cost-driver output or event quantities. The Federal Reserve's functional cost rates are a popular source for these standard costs. Manufacturing companies that use these published rates thus risk using misleading productivity data when their actual unit costs differ from the published averages. Manufacturing companies can solve this problem by implementing their own $\mathrm{ABC}$ measurements to purify their results. $\mathrm{An} A \mathrm{ABC}$ calculation engine gives them their true rates and assures that their calculated profits will reconcile with their actual spending reported in their general ledger system and to management. In using the overly detailed information, many organizations over- engineer the size of their initial $\mathrm{ABC}$ system well beyond diminishing returns. As a result, the project can die because it takes too long and because of skepticism about the minutia and details. Concerning failure 
to connect information to action, after calculating profitability by service line and by customer, some manufacturing companies fail to act on the data. For example, they hesitate to abandon unprofitable customers, increase promotion of profitable service lines, or alter customer behavior in ways that generate greater profits. Manufacturing companies lose money on more than half of their customers but make it up on the few customers that are profitable. Therefore, it is critical to know which customers make or lose money, what is the per-customer profit or loss, and why. Manufacturing companies must then ask how long they can perpetuate making decisions without having reasonable answers to those questions.

\section{Theoretical framework}

This study applies the concept of the resource-based view and the contingency theory to help clearly understand the relationship among variables in the conceptual model. The resource-based view is defined by seeing resources as all assets, capabilities, organizational processes, firm attributes, information and knowledge controlled by a firm (Barney, 2011). He proposed that firms have a competitive advantage when they create successful strategy, based on firms' resources that cannot be duplicated by a current or potential competitor. The theory goes on to state that resource and capability must be rare, valuable, non-imitable, non-substitutable, and nontransferable. The resourcebased view explains how firm resources and capabilities drive differences in firm's performance. Resources and capabilities of the firms are key to create, sustain competitive advantage and achieve superior performance (Barney, 2011; Grant, 2016). Thus, this research proposes cost accountant competency, corporate resources facilitation and $\mathrm{ABC}$ effectiveness as resource and capability to create a sustainable competitive advantage and performance. Firms that have more ABC effectiveness (cost driver fitness, cost calculation accuracy, cost information creditability, and cost reporting usefulness) will have more competitive advantage (production process efficiency, cost advantage and productive planning proficiency) and lead to greater financial performance.

\section{The contingency theory}

The contingency theory to management accounting is based on the premise that there is no universally appropriate management accounting system that applies equally well to all firms in all circumstances (Emmanuel, Otley\& Merchant, 2010). This suggests that the particular features of an appropriate accounting system will depend upon the specific circumstances in which firms must find it. How effective the design of an accounting system is depends on that ability to adapt to changes in external circumstances and internal factors in order to assist managers in achieving goals. Contingency theory suggests that the need for efficient organizational structures, processes and competent management accounting system is contingent on organizational and environmental characteristics. This forces influence changes in the structure, and sophisticated cost management system or advance cost accounting techniques such as ABC leads to enhances firm performance (Cagwin\&Bouwman, 2012; Drury \&Tayles 2005). Thus, this research indicates the price competitive force that should stress firms to resort to $\mathrm{ABC}$ effectiveness in order to gain competitive advantage for organization and increased financial performance.

\section{New institutional theory (NIS)}

This theory according to Scott (2007) states that organizations gain legitimacy and survive by conforming to the expectations and demands posed by institutional environments. Thus NIS argues that organisations are shaped according to beliefs, fashions, and desires of important external institutions. However, NIS research has focused almost exclusively on not-for-profit organizations and public agencies not subject to market forces. Often NIS theory dichotomizes between public and private sector organizations, arguing that the former are subject to institutional pressures, whereas market forces shape the latter. Thus NIS theorists have been able to neglect the effects of economic pressures, often by assuming that institutional and market pressures are mutually exclusive and each set of pressures is confined to a particular class of organizations.

All organizations may face institutional pressures (Scott, 2007) and not merely private firms in competitive markets face pressures for efficiency. However, different levels and functional divisions within organizations face different environmental pressures. In this case, commercial departments were happy to adopt ABC as stipulated in European legislation responsible to satisfy external regulators. Production departments and engineers also welcomed ABC, believing that it would provide better cost information for business decisions. However, as the balance of power swung from the engineers to the commercial department, and engineers' doubts about ABC grew, they began to resist and manipulate $\mathrm{ABC}$. Yet $\mathrm{ABC}$ remained and the commercial departments remained satisfied with it. This is an ongoing saga but it is evident that $\mathrm{ABC}$ adoption could not be understood merely by recourse to external institutional pressures - efficiency issues also arose. In addition, the presence of differentiated departments dealing 
with different external pressures, and pursuing different agendas affected the adoption, operation, and evaluation of $\mathrm{ABC}$. To understand $\mathrm{ABC}$ it was necessary to study internal dynamics of conflict and resistance.

In the last decade a growing number of accounting scholars have studied organizational accounting practices through institutional theory in its economic and sociological variants (Perez \& Robson, 2009). This has been stimulated by the growing number of organizational researchers adopting NIS because of its challenge to prevailing research beliefs that organizations are bounded, relatively autonomous, and comprised of rational actors. Since the 1970's NIS researchers have demonstrated the importance of cultural, normative, and cognitive factors in organisational analysis in sharp contrast to the realist and deterministic approaches of many previous organizational theories (Scott, 2007).

\section{The production theory}

According to koskela (2010), there are three production theories for creating products and services: Transformation, Value generation and Flow.

Transformation theory: The transformation theory, which is based on input, process and output (IPO) is the dominant production theory in use today. It is reductionist; it breaks down every process into individual tasks performed by specialists. Activities are tightly organized and controlled; it is consistent with Scientific Management and traditional cost accounting. It seeks to optimize the entire production phase by optimizing each individual task, assuming that minimizing the effort and cost of each task translates directly to maximum throughput and customer value.

Value generation theory: Value generation focuses on delivering maximum value to the customer. All tasks and activities are measured and evaluated based on this concept. Activities that don't deliver value are not performed. Production efficiency is redefined as the efficient delivery of value to the customer. There is a strong focus on quality. If the customer does not want or value what is delivered, then activities that lead to these outcomes are considered waste. The theory is based on the assumption that a value focus will optimize the overall process of value delivery and lead to process optimization based on the larger context of value generation. The theory has a focus on quality, profits and ROI, not costs. Note that a process which transformation theory might consider efficient and successful might be judged from the value generation point of view as a failure. Flow theory: Flow theory focuses on realizing value quickly, minimizing inventory and reducing the total latency of production. Fast turnaround lets the market control what is wanted. Production does not occur unless there is a specific request for a product or a very strong expectation of such a request. Flow seeks to increase the tempo of production.

These three theories are very interesting and have many implications. For example, the Chinese economy is successful because it is a source of low cost inputs, maximizing value according to the transformation theory of production. The Chinese production model however, greatly slows down flow and can result in tremendous waste, since customer value is not the focus. By contrast, Japanese companies as exemplified by Toyota above all, focus on value generation and flow. These companies are not afraid to locate in high cost locations, because they know that the cost of inputs is not the only thing that is valuable to control. High cost locations are able to achieve faster flow and realize higher customer value (and therefore higher profits).

Outsourcing of services is another instance, where these theories of production have unexpected ramifications. Outsourcing is about reducing the cost of inputs and therefore reducing the cost of specific tasks, but flow and customer value creation are reduced, due to time lags, cultural issues and communication difficulties. On balance, outsourcing may not deliver the benefits its advocates expect and there are some indications that companies are starting to realize this.

\section{Activity-Based Costing (ABC)}

$\mathrm{ABC}$ is an economic model of an organization's production-related activities (Kaplan, 2004). The causal relationship between products and customers that consume resources is determined by tracing cost based on the factor (cost driver) that causes or correlates highly with a product's or customer's use of an activity's resources. ABC traces cost to products based on volume-related factors, such as unit, batch and product-level cost drivers as well as nonvolume-related cost drivers, such as product diversity, complexity and quality. Surveys and interviews with managers using $\mathrm{ABC}$ indicate that it is used to support a wide range of economic activities, such as product mix, 
pricing and outsourcing decisions (Cooper \& Kaplan, 1992). However, evidence of enhanced financial performance resulting from firms adopting $\mathrm{ABC}$ is somewhat limited (Cooper \& Kaplan, 2008). Noreen, (2011) examined the conditions necessary for ABC to provide relevant data for dropping a product from the firm's product mix and for designing a product. For these decisions, a firm's costs must be separable into cost pools, each of which is dependent upon a single cost driver.

Secondly, it requires that the cost in each pool must be proportional to the level of activity in the cost pool. Consequently, the cost function used to model each pool must be linear with a zero intercept. Finally, it requires that the activities of each cost pool must be separable with respect to the products they are used to produce. This precludes any form of dependencies between products in the production process. The conditions specified by Noreen (2011) were developed for specific decision contexts. However, these conditions alert the ability of ABC to accurately trace the cost of resources to products. Consequently, the conditions necessary for ABC to provide highly accurate product cost may be quite stringent. $\mathrm{ABC}$ has been criticized for its usefulness in supporting short-term decisions (Theeuwes\&Adriaansen, 2014). ABC traces the cost of resources to production activities and from activities to the products that use an activity's resources during production. Consequently, ABC is based on the resources used in production (Cooper \& Kaplan, 2008). However, many of the firm's resources are contracted in advance of usage, such as rent on factory equipment, or influenced by management policy, such as retaining workers in periods of excess labor capacity. In the short run, the cost of these resources may not be controllable by the firm. Therefore, the resources used in production may not equal the resources supplied to production, i.e. the resources the firm is committed to acquiring. Consequently, in the short run, the cost behavior represented by $\mathrm{ABC}$ for making production-related decisions may not reject the level of spending the firm will incur from these decisions (Salafatinos, 2016). To address this issue, Salafatinos (2016) proposes using incremental analysis based on the relationship between the demand for resources and the structural level at which they are supplied. Over a sufficiently long time period, a firm may adjust its contractual relationship with suppliers and its management policies to match the use and supply of resources. Under these conditions, ABC will reject the level of spending the firm may expect to incur from production related decisions, i.e., the cost of resource usage is equivalent to the resources supplied to production. $\mathrm{ABC}$ has also been criticized for its failure to incorporate constraints into production-related decisions (Spoede, Henke, and Umble, 2014). Under ABC, the capacity of production activities is incorporated indirectly into the selection of a product mix. An activity's cost is divided by its practical capacity to derive a cost-driver rate for tracing cost to the products that use an activity's resources. Over a short to intermediate time horizon, a firm's management may be unable to adjust an activity's capacity to meet the firm's production needs. However, ABC fails to consider this limitation in selecting a product mix. In the long run, the capacity of production activities can be adjusted to meet the demand for the firm's products. However, even then, cost-driver rates are predicated on specific levels of production capacity. Analysis of this capacity is critical for understanding the production opportunities inherent in cost driver rates and for evaluating whether these capacity levels are optimal for the firm. Kee, (2015) and Malik and Sullivan (2015) demonstrate that activity- based cost may be integrated with the capacity of production activities in order to incorporate bottleneck activities into product-mix decisions. However, the basis for making these decisions remains $\mathrm{ABC}$. Throughout the remainder of the paper, this approach will be used to represent the selection of a product mix with $\mathrm{ABC}$.

\section{The objectives of Activity-Based Costing}

$\mathrm{ABC}$ was promoted at the time of introduction as a method of reducing the inaccuracies experienced with traditional costing systems that arise from prevalent technology and competition (Dodd \& Lavelle, 2012). The perceived downside to these traditional systems is the use of a single cost driver for assigning overhead costs to products. As a result, this costing system fails to account for the changes occurring to cost structures in the modern business environment, where direct labour is no longer accounting for the majority of a products cost (Khanna, 2012). He argued that the primary failings of traditional costing systems are the inability to provide useful feedback or understand and allocate overhead costs. Traditional systems also have the potential inability to account for the size and diversity of products, as a larger or more complex item that may produce more revenue may also consume a larger than presumed overhead cost (Doyle, 2002). Brewer, Brownlee and Juras, (2003) argue that these issues have the potential to reduce a company's overall profitability. In hindsight, this may appear obvious but the founders of ABC believe that, "most companies do not recognize that their traditional costing systems provide unreliable and distorted cost information until their profitability and competitiveness have deteriorated" (Cooper \& Kaplan, 2008, cited in Bidanda\& Golden, 2013). 
As a result of traditional costing inaccuracies, it was apparent that a costing technique with a more adequate level of accuracy was required (Khanna, 2012). As ABC assigns indirect costs to products, services and customers depending on the actual usage of resources, proponents of $\mathrm{ABC}$ argue that this system fits the requirement. However, one of the greatest misconceptions about $\mathrm{ABC}$ is that the system is not applicable to service organizations (Compton, 2016). On the contrary, the utility of ABC has expanded beyond the manufacturing role, branching to improve the accuracy of non-manufacturing costs, as well as enabling profitability analysis for customers and other business functions (Chenhall\&Langfield-Smith, 1999). As a result, research exploration has extended to the use, importance and effectiveness of $\mathrm{ABC}$ in non manufacturing firms across a wide range of industries. $\mathrm{ABC}$ is argued to be of similar importance in the service sector due to the need to reduce the costs of services for retaining competitive capabilities (Clarke \& Mullins, 2011).

\section{Possibilities of implementation of the ABC method}

There are very many factors that lie at the bedrock of the successful implementation of the ABC-system (ActivityBased Costing) in the steel industry of Nigeria. Based on a vast study carried out in the specialty literature and taking into account the opinions of famous experts, Ness \&Cucuzza, (2005) pointed out seven main factors namely: the management's support, the staff training, the knowledge sharing, the resources, the connection between the reward and evaluation of performance, the forging of technological information, the concern for the implementation of other systems. The specialty studies have proved that the management's support is the main factor in the successful implementation of an accounting system and especially of the ABC-system. Why has the staff training been mentioned firstly as main factor? The reason is very simple. The successful implementation of the ABC-system can be carried out only with the help of the employees, since they represent the basis of the pyramidal organization. In other words, any innovation must rely on a very strong management support in order to be successful. The management must concentrate its efforts on the establishment of the necessary resources, of the goals as well as on the formulation of efficient strategies for the implementation of the ABC-system in the companies of the steel industry in Romania. The management must encourage the use of the information supplied by the ABC-system, especially by the communication with its employees. Training greatly helps the company staff to understand the difference between the ABC-system and the other existing, traditional cost systems such as the stage-based method or the order-based method. In this respect, Player \& Keys, (2015) present some of the advantages of the ABCsystem:

1. The obtained production costs are much closer to reality than those obtained in the case of the methods traditionally used in Romania and this is due to the use of a very advanced production technology (an essential and successful factor of the ABC-method), where the indirect costs have the greatest share in the overall production costs.

2. At present, in most of the companies, including the steel companies, an increase of the unproductive activities (non-value) can be noticed, and the ABC-method permits the allocation of the majority of indirect costs to manufactured goods, performed work or rendered services.

3. The ABC-method focuses its attention on the real nature of cost behaviour, thus helping to identify the nonvalue activities (which do not add value to products).

4. It uses multiple cost inductors that reveal the direct relationship cause-effect between the expenses to be allocated and the allocation bases employed.

5. It is flexible in the cost allocation to the manufactured goods, performed work or rendered services, customers or to different strategic segments.

6. It resorts to the re-structuring of the supporting activities within the main activities. Compared to the method of expenses centres, the latter did neither allow the re-structuring of activities according to transversal processes nor did it surpass the limit of the established responsibility centres. Besides, the ABC method does not provide auxiliary centres, the costs of all the centres being charged on the costs of the goods without secondary allocation.

7. It uses dash-boards built on the basis of some carefully selected steering indicators, thus supplying reliable long-term information, appropriate for making long-term strategic decisions.

8. It is compatible with other management instruments.

9. It has the possibility to adapt the General Plan of Accounts in our country to the specific nature of the ABCmethod within the companies of the steel industry of Nigeria.

Besides, Ness \&Cucuzza, (2005) state that staff training encourages knowledge sharing, offering at the same time a superior economic measurement of information. The staff training should be achieved both on the vertical and on the horizontal of the management system, from the manager to the directly manufacturing worker. This training can 
be performed by: lecturing, discourses, explanatory projects or training on the spot, performed by experts. Regarding the knowledge sharing, the specialty literature refers to two manners lying at the extremities. The first refers to the operating manner of the ABC-system that is known thoroughly only by accountants or specialists (accounting department), in this situation existing the imminent danger of being used only for their own purposes. One of the main reasons of the failure of the ABC-system implementation is that accountants (specialists) are the owners thereof and they do not share it with the others (non-accountants / non-specialists). The second situation refers to the manner of sharing among accountants and non-accountants, fact that surely leads to the successful implementation of the ABC system (Activity-Based Costing). From this point of view, not only accountants or specialists but also the other persons (the employees) must be considered as owners of the system. All the employees of a company should be involved in the initial decisions, to invest in the method of Activity-Based Costing, in the project and implementation thereof. Thus the chances of the ABC-system to be promoted and supported by non-accountants or non-specialists will grow significantly and will be successful.

\section{Applications of activity-based costing}

Innes and Mitchell (2005) survey of activity-based costing practices in the $251 \mathrm{UK}$ companies listed in The Times 1000 and found out that $19.5 \%$ of the respondents had adopted ABC and $27.1 \%$ were considering its adoption. The extent of its adoption in the non-manufacturing sector had not been found significantly different from that found in manufacturing concerns. The ABC users had considered its applications in the areas of cost reduction, product/service pricing, performance measurement, \& improvement, and cost modeling. The inventory valuation use had the lowest adoption rate amongst ABC users. Dugdale and Jones (2007) follow-up survey to Innes and Mitchell questionnaire of large UK firms adopting activity-based costing has found that only three companies used ABC for stock valuation as against reporting of 14 companies, when strong definition of ABC was applied. The ABC adoption / under consideration rate has fallen to $17.5 \%$ and $20.3 \%$ from $21 \%$ and $29.5 \%$ respectively. The highest adoption rate is in the financial sector. In terms of scale, the median activity-based cost accounting systems design included 40 (1994: 14) cost objects, 52 (1994: 25) activities, 22 (1994:10) cost pools and 14 (1994: 10) cost drivers. The ABC rejection rate has increased from $13.3 \%$ to $15.3 \%$ during this period. Cost reduction, pricing, performance measurement / improvement and cost modeling continued to be the most commonly used areas for activity-based costing. The top management support to the ABC implementation initiative and to a lesser extent, with its use to support quality initiative determined its success in a survey of 132 US companies, Foster and Swanson (2012) found that all of them were using activity-based cost management, when they responded. The decision use of ABCM, management use of dollar improvement and the overall net benefits as success measure yields the highest explanatory power. Groot (2009) survey of US food and beverages industry found that $18 \%$ of the respondents had implemented activity-based costing and 58\% were considering its implementation. Joshi (2001) in a survey of 60 large and medium-sized manufacturing companies in India found adoption rate of $20 \%$ for activity-based costing, $13 \%$ for activity-based management, and $7 \%$ for activity-based budgeting. The size in terms of total assets has been found to be significant factor in adoption of these contemporary management accounting techniques. The traditional management accounting techniques have been emphasized more vis-à-vis contemporary techniques because of higher perceived benefits. Narasimhan and Thampy (2002) designed activity-based costing system for ascertaining service cost for different customers with a case study of two branches of a large Indian private sector bank. The use of activity-based cost information in benchmarking, branch network restructuring, business process outsourcing, and identification of value-added and non-value added activities have been argued.

\section{The general structure of the ABC model}

Since in the late 1980s, many industries have successfully employed ABC to improve operational performance. $\mathrm{ABC}$ has continued to provide relevant and accurate information about cost management. In addition, because the $\mathrm{ABC}$ system focuses on activities rather than products, it helps prevent distorted product cost information that can arise from the use of traditional costing systems (Gunasekaran\&Sarhadi, 2008; Cooper \& Kaplan, 2008). The basic assignments of the ABC model are to identify the activities of an organization, calculate the cost of each activity, and then cost the product based on activity consumption (Gunasekaran\&Sarhadi, 2008). Moreover, the ABC approach can be used to allocate various activities to related resources. Costs are appropriately allocated to selected cost objects by using the cost driver1 of each activity. Therefore, accuracy of product cost is contingent upon both calculations of activity cost and cost driver volume. The structure of the ABC model contains information relevant to organizational resources, activities, and cost objects. The implication is that the cost object is the cause of activities and those resources exist solely to carry out those activities. After the resource costs have been assigned to their respective products. By obtaining these measures, activity drivers become a way of assigning the cost of activities to the actual cost object (Spoede, Henke and Umble 2014). Hence, in the ABC system, the total cost of a 
product also includes the cost of all activities required to produce or handle it. In the ABC model, accuracy frequently depends upon the details of the $\mathrm{ABC}$ model and the type of activity driver used. There are three types of activity drivers (Compton, 2016; Anasta, 2011):

1. Transaction drivers, which count each time an activity takes place;

2. Duration drivers, which represent the time taken for each activity and also takes into account variation; and

3. Intensity drivers which directly cost the resources used each time an activity takes employed all three types of activity drivers.

\section{Activity-based costing effectiveness and production process efficiency}

$\mathrm{ABC}$ effectiveness consists of cost driver fitness, cost calculation accuracy, cost information creditability, and cost reporting usefulness. Cost driver fitness and cost calculation accuracy may make the employees, across functions, to understand various costs and accurate costs (Groot, 2009). In addition, cost driver fitness and cost information creditability will enable to analyze the cost, labour time, production time, and raw material utilization and may reduce production of off-specification material to identify the value added and non value added activities. These activities will make production processes more efficient from those which no added value that can be eliminated or reduced such as process bottleneck, wait material, material loss leading to achieve overall production process efficiency, (Theeuwes\&Andriaanson, 2014).

Cost driver fitness, cost information creditability and cost reporting usefulness from $A B C$ effectiveness assist management to understand and to analyze production processes and their effects on the cost. As process efficiency is the successive identification and elimination waste in operating activities. Cost driver fitness and cost information creditability help to reengineer process, eliminate non-value-added activities, without unnecessary delay, errors, decrease time to perform activity, select the low-cost activity and share activities with other products to yield economies of high-volume production (Lewis, 2015; Snead, 2012; Doyles, 2002). Using cost reports about every activity, material in the product chain and activity analysis guides management to process improvement leading to production process efficiency (Joshi, 2001). Thus, cost driver fitness, cost calculation accuracy, cost information creditability, and cost reporting usefulness identify opportunities to improve business process effectiveness and efficiency by determining, redundancies, reducing non value-added activities, and decreasing setup time and activities of production lead to production process efficiency.

\section{Methodology:-}

This study appraised the effect of Activity Based Costing (ABC) on corporate productivity. This study made use of the survey design to achieve the objectives of the study. The population of the study was made up of 1,356 manufacturing staff members of companies in Nigeria. A sample size of 309 staff was randomly selected using the Taro Yamane formula. According to Yamane (1984) a sample size is obtained as:

$\mathrm{n}=\mathrm{N} /\left[1+\left(\mathrm{Ne}^{2}\right)\right]$

Where; $\mathrm{n}=$ the sample size,

$\mathrm{N}=$ the population,

$\mathrm{e}=$ the error limit $(0.05$ on the basis of $95 \%$ confidence level $)$

$\mathrm{n}=1356 / 1+1356 \times 0.05^{2}=308.88$ approximately 309

The sampling procedure used for the study was the simple random sampling technique. This was because it was assumed that the population is homogeneous, all the elements were identical and all the staff in the defined population had equal chance of being selected. The data for this study were gathered using a 30 -item questionnaire. The data were collated, extracted and arranged in means, standard deviations and percentages where necessary. This enabled the determination of the statistical analytical technique employed for each research hypothesis of the study.

\section{Research hypotheses}

$\mathrm{H}_{\mathrm{o} 1}$ : Cost driver fitness does not significantly affect production process efficiency.

$\mathrm{H}_{\mathrm{O} 2}$ : Cost calculation accuracy does not significantly affect production process efficiency.

$\mathrm{H}_{03}$ : Cost information creditability does not significantly affect production process efficiency.

$\mathrm{H}_{\mathrm{o} 4}$ : Cost reporting usefulness does not significantly affect production process efficiency.

The study made use of the multiple regression model. In order to test the hypotheses, the researchers followed the approach prescribed by Baron and Kenny (1986) thus:

$\mathrm{PPE}=\mathrm{b}_{0}+\mathrm{b}_{1} \mathrm{CDF}+\mathrm{b}_{2} \mathrm{CCA}+\mathrm{b}_{3} \mathrm{CIC}+\mathrm{b}_{4} \mathrm{CRU}+\mathrm{ei}$ 
Where:

$$
\begin{array}{ll}
\text { PPE } & =\text { Production Process efficiency } \\
\text { CDF } & =\text { Cost driver fitness } \\
\text { CCA } & =\text { Cost calculation accuracy } \\
\text { CIC } & \text { = Cost information creditability } \\
\text { CRU } & \text { Cost reporting usefulness } \\
\mathrm{b}_{1}-\mathrm{b}_{4} & =\text { Unknown coefficients to be estimated } \\
\mathrm{b}_{0} & =\text { Unknown constant to be estimated } \\
\mathrm{ei} & \quad=\text { Error term }
\end{array}
$$

\begin{tabular}{|c|c|c|c|c|c|}
\hline VARIABLE & \multicolumn{2}{|c|}{$\begin{array}{l}\text { ESTIMATED } \\
\text { COEFFICENTS }\end{array}$} & $\begin{array}{l}\text { STANDARD } \\
\text { ERROR }\end{array}$ & T-Statistic & P- Value \\
\hline Constant & \multicolumn{2}{|l|}{20.086} & 2.633 & 7.629 & .000 \\
\hline $\mathrm{CDF}$ & \multicolumn{2}{|l|}{.166} & .046 & 3.597 & .000 \\
\hline $\mathrm{CCA}$ & \multicolumn{2}{|l|}{.369} & .068 & 5.393 & .000 \\
\hline $\mathrm{CIC}$ & \multirow{2}{*}{\multicolumn{2}{|c|}{-.086}} & .045 & -1.940 & .053 \\
\hline CRU & & & .066 & 4.043 & .000 \\
\hline \multicolumn{6}{|c|}{$\mathrm{R}=0.815$} \\
\hline \multicolumn{2}{|l|}{ R-Square } & & & & \\
\hline \multicolumn{2}{|l|}{ Adjusted R-Square } & & & & \\
\hline \multicolumn{2}{|l|}{ SEE } & & & & \\
\hline \multicolumn{2}{|l|}{ F - Statistic } & $=$ & & & \\
\hline \multirow{2}{*}{\multicolumn{2}{|c|}{$\begin{array}{l}\text { Durbin Watson Statistic } \\
\text { t-statistics (table value) at two tail }\end{array}$}} & $=$ & & & \\
\hline & & $=$ & & & \\
\hline
\end{tabular}

Results:-

Table 1:-Regression results of the relationship between activity based costing (abc) and corporate productivityDependent variable: production process efficiency (ppe)

The coefficient of determination R-square of 0.706 implies that $70.6 \%$ of the sample variation in the dependent variable, corporate productivity, is explained or caused by the explanatory variables while $29.4 \%$ is unexplained. This remaining $29.4 \%$ could be caused by other factors or variables not built into the model. The high value of $\mathrm{R}$ square is an indication of a good relationship between the dependent and independent variables. The adjusted $\mathrm{R}^{2}$ of 0.690 shows that the regression line captures more than $69 \%$ of the total variation in corporate productivity caused by variation in the explanatory variables specified in the equation with less than $31 \%$ accounting for the error term. Testing the statistical significance of the model, the F-statistic computed as 20.124 is greater than the table value of 2.60 at df $1=4$ and df $2=242$. The test of autocorrelation using DW test shows that the value of 2.580 falls within the inconclusive region of DW partition curve. Hence, we can clearly say that there exists no degree of autocorrelation amongst the variables.

For hypothesis one, the computed t-statistic is 3.597 with P-value of 0.000 , less than the $5 \%$ level of significance with degree of freedom $\mathrm{n}-2$, the null hypothesis is rejected and the alternative accepted, meaning that Cost driver fitness significantly affects production process efficiency. Hypothesis two shows the computed t-statistic as 5.393 with a P-value of 0.000 which is less than the 5\% level of significance with degree of freedom $n-2$. Therefore, the null hypothesis is rejected and the alternative accepted, meaning that Cost calculation accuracy significantly affect production process efficiency. For hypothesis three, the computed t-statistic is -1.940 with a P-value of 0.053 is greater than $5 \%$ level of significance with degree of freedom $n-2$. Since the computed value is less than the table value, the null hypothesis is accepted while the alternative rejected, meaning that Cost information creditability does not significantly affect production process efficiency. Hypothesis four shows that the computed t-statistic is 4.043 with a P-value of 0.000 less than the 5\% level of significance with degree of freedom $\mathrm{n}-2$. Therefore the null hypothesis is rejected and the alternative accepted, meaning that Cost reporting usefulness significantly affect production process efficiency.

\section{Discussion of findings:-}

Based on the analysis and empirical results, the study revealed that all the estimated coefficients of the regression parameters have the positive signs except Cost Information Credibility (CIC) which has a negative sign. These 
coefficients conform to our a-priori expectation that $\mathrm{x} 1$, x2etc could either be positive or negative. The implications of these signs are that the dependent variable is positively influenced by Activity Based Costing. This means that an increase in the independent variable will bring about an increase in the dependent variable-corporate productivity, mirrored by Production Process Efficiency (PPE). Specifically, a 1\% increase or decrease in activity based costing, mirrored by CDF, CCA, CRU and CIC, will lead to an increase or decrease in corporate productivity with a margin of approximately $0.166,0.369,0.269$ and -0.086 respectively.

The study revealed that cost driver fitness and cost reporting usefulness have a significant positive effect on production process efficiency. The cost driver fitness has prompted many firms to reengineer business processes by monitoring each process and then, eliminating or improving the processes which are non-value added (Player \& Keys, 2015). Additionally, this study is in line with the work of Ness \&Cucuzza, (2005) who found out that cost driver fitness has a significant relationship with production process efficiency. This result is also in line with the findings of Effiong\&Beredugo (2015) who stated that balanced scorecard and strategic cost management are complementary measures used in assessing the performance of companies in order to align business activities to the overall strategic objectives and ensure both short term and long term productivity through financial and non financial planning, implementation and performance evaluation processes

The study also revealed that cost reporting usefulness and cost calculation accuracy do significantly affect production process efficiency. These results agree with the findings of Effiong\&Oti (2012) who concluded that materials, labour and overheads are the main and major costs affecting and influencing every manufacturing process. When these costs are well controlled and monitored productivity is highly enhanced in the manufacturing sector and when they are not well control poor productivity is the outcome. The findings reveal that productivity of the production factors highly determines the level of profitability of the company. These results were also supported by the works' of Grant, (2016) and Clarke \& Mullins, (2011); who found out that there exists a positive relationship between cost reporting usefulness and cost calculation usefulness with production process efficiency.

Finally, the study revealed that cost information credibility does not significantly affect production process efficiency. This result is in line with the work of Khanna, (2012) who found out that cost information credibility has negative relationship with production process efficiency. The more credible information in a typical production setting the more workers reduce their performance resulting in low productivity. This indicated that the firms studied used more cost driver fitness, cost calculation accuracy and cost reporting usefulness to provide greater production process efficiency.

\section{Conclusion and Recommendations:-}

Activity Based Costing utilizes the cost driver concept to link the product costs to production knowledge. How a product is produced, how much time is needed to perform an activity and finally how much money is absorbed by performing this task are answered by $\mathrm{ABC}$ system. Cost driver fitness correlates activities and resources usage for easy measurement and convenience practice. It is useful in budgeting and performance evaluation. It provides the difference between resources used and provided. Cost driver fitness elicits information about cost components and activities in process that affect cost. It separates value-adding from non-value adding activities thereby promoting production process efficiency.

Cost calculation accuracy reduces the risk of distortion and provides accurate data for product/service costing. Cost information creditability provides valuable cost information for decision making purpose. Problems and opportunities are identified which help managers in making well informed decision and promote production efficiency. In the same vein, cost reporting usefulness assist in planning and control. This enhances job performance and triggers efficiency in production. These are all indicative of the correlation between activity-based costing and productivity.

Based on the findings of the study, the following recommendations are made: Accurate cost calculation which is a component of $\mathrm{ABC}$ is recommended for greater production efficiency; activities which do not add value to production or service delivery should be eliminated using multiple cost drivers in $\mathrm{ABC}$ process. Timely disclosure of cost information for effective planning and control in production process should be encouraged; Chief Executive Officers of manufacturing companies should design appropriate incentives for motivating employees of new systems implementation. 


\section{References:-}

1. Adams, S.G. (1996). Engineering design - A systematic approach, London: Springer-Verlag.

2. Anastas, U. (2011). Measuring the impact of product mix heterogeneity on manufacturing cost. Accounting Review, 79(3):363-387.

3. Barney, R.S. (2011). Measuring manufacturing performance: A new challenge for manufacturing accounting research. Accounting Review, 2(7) 686-705.

4. Beheshti (2004). An empirical analysis of manufacturing overhead cost drivers. Journal of Accounting and Economics, 19: 115-137

5. Ben-Arieh, D \&Qian, L. (2013). Activity-based cost management for design and development stage. International Journal of Production Economics, 83:169-183.

6. Bidanda, Y. \& Golden, K. (2013). Pillsbury: Customer driven reengineering. Harvard Business School, 9:125-144

7. Bjornenak, O. R. \& Olson, t. R. (2009). From ABC to ABM: Does activity- based management automatically follow from an activity-based costing project? Management Accounting Review 74(5): 54- 57.

8. Brewer, R.W., Brownlee, L. \&Juras, H. P. (2003). The role of empirical research in management accounting. Accounting, Organization and Society. 11(5):429-452.

9. Burke, E. \& Huff, B.M. (2005). The cost effects of component commonality: A literature review through a management accounting lens. Working paper presented at the 6th Management Accounting Research Conference, Twente University, Holland.

10. Cagwin, H. \&Bouwman, M.A. (2012). Contribution margin analysis: no longer relevant/strategic cost management: The new paradigm'. Journal of Management Accounting Research, Fall: 1-8

11. Chenhall, V. \&Langfield-Smith, S. (1999). Appropriateness and impact of platform-based product development. Management Science, 47(1):52-68.

12. Clarke, T. \& Mullins, J. (2011). Measuring product structures to improve demand-supply chain efficiency. International Journal of Technology Management, 23(6): 578-598.

13. Compton, R. (2016). Tektronix: Portable Instruments Division (A) and (B). Harvard Business School 9:138142

14. Cooper, R. \& Kaplan, R. S. (2008). How cost accounting distorts product costs.' Management Accounting Review, 69:20-27.

15. David, S. \&Alson, F (2003). Revolutionizing the factory Door, Management Accounting 68 (11) 22.

16. Dodd, A.S. \& Lavelle (2012). Accounting lag: the obsolescence of cost accounting systems. In Kim B. Clack et al., The uneasy alliance: Managing the productivity-technology dilemma.

17. Doyles, A. S. (2002). Cost accounting: A revolution in the making. $\quad$ Corporate Accounting, Spring: 1016

18. Drucker, P. (1992). Measure costs right: make the right decisions. Harvard Business Review, Sept/Oct: $96-103$

19. Drury, C.R. \&Tayles, R. S. (2000). The design of cost management systems, $1^{\text {st }}$ edition.' Englewood Cliffs: Prentice Hall.

20. Drury, C. R. \&Tayles, R.S. (2005). Profit priorities from activity- based costing. Harvard Business Review, 3: 130-135.

21. Dugdale, A. R. \& Jones, K.S. (2007). Activity-based cost management making it works."McGraw-Hill Inc.

22. EFFIONG, S. A. \& BEREDUGO, S. B. (2015). Balanced scorecard and strategic cost management: recipes for productivity rating of Nigerian manufacturing companies; Open Journal Of Finance, 2(1), 2 12.

23. EFFIONG, S. A.,\& OTI, P. A. (2012). Analytical evaluation of cost elements and their influence on productivity of manufacturing firms; Journal of Finance and Iinvestment Analysis. 1 (3), 171- 180.

24. Emmanuel, I., Otley, I.D. \& Merchant, C.P. (2010). Measuring the cost of ownership. Journal of Cost Management, Fall, 42-51

25. Foster, R.S. \&Swansan, W. O. (2012). Cost and effect: using integrated cost systems to drive profitability and performance. Boston, MA:

Harvard Business School Press

26. Goldratt, R. A. (2013). Changing competitive dynamics in network industries: An exploration of Sun Microsystems' open system strategy. Strategic Management Journal, 14: 351-369

27. Grant, M. (2016). Manufacturing overhead cost driver analysis. Journal of Accounting and Economics, 12: 309-337 
28. Groot, H. L. (2009). Architectural innovation: the reconfiguration of existing product technologies and the failure of established firms. Administrative Science Quarterly, 35(1): 9-30

29. Gunasekaran, K. \&Sarhadi, M. (2008). Implementation of activity- based costing in manufacturing. International Journal of Production Economics, 5(6):231-242.

30. Innes, J. R. and Mitchell, L. (2005). Metrics thermostat. Journal of Product Innovation Management, 18(3): 134-153

31. Joshi, J. (2001). A pragmatic approach to product costing based on standard time estimation. International Journal of Operations \& $\quad$ Production Management, 19 (7): 738-755

32. Johnson, H.T. Kaplan, R. S. (2007). Relevance lost: The rise and fall of management accounting'. Boston, MA: Harvard Business School Press

33. Kaplan, R. (2004). In defense of activity-based cost management: ABC models can play many different roles to support a company's operational improvement and customer satisfaction programs, Management Accounting Review 74(5):12-20.

34. Khanna, J.B. (2012). Measuring the ROI of reuse. Object Magazine. 49-54

35. Kee, R. (2015). Integrating activity-based costing with the theory of constraints to enhance productionrelated decision making, Accounting Horizons 9 (4) 48-61.

36. Kim, G., Park, C.S \& Kaiser, M. J. (2007). Pricing investment and production activities for an advanced manufacturing $\quad$ system. Engineering Economist, 42(4):303-324.

37. Koskela, K. (2010). Design for product variety: Key to product line $\quad$ structuring. ASME Design Engineering Technical conference

38. Lewis, R. J. (2015). Activity-based models for cost management systems. Quorum Books, Westport, CT.

39. Malik, M. V. \& Sullivan, K. (2015). Design for variety: development of complexity indices and design charts. ASME Design Enginering Technical Conference, Sacramento, CA, USA

40. Narasimhan, P. \&Thampy, M. H. (2002). 'Component commonality: models with product-specific service constraints'. Production and Operations Management, 11(2):199-215.

41. Ness, J.A. \&Cucuzza, T.G. (2005). Tapping the full potential of ABC. Harvard Business Review, 95: 130138

42. Noreen, R.S. (2011). Yesterday’s accounting undermines production. Harvard Business Review, July/August: 95-101.

43. Ozbayrak, M., Akgun, M. \&Turker, A. K. (2004). Activity-based cost estimation in a push/pull advanced manufacturing system. International Journal of Production Economics, 87:49-65.

44. Perez, A. \& Robson, J. R. (2009). Components commonality effects on inventory costs. IEE Transactions, 28(2):93-104

45. Player, M. \& Keys, U. (2015). Component sharing in the management of product variety: a study of automotive breaking systems. Management Science, 45(3): 297-315

46. Salafatinos, W. (2016). The productivity paradox. Harvard Business $\quad$ Review, 64(4): 55-59

47. Scott, J. F. (2007). Activity based costing; A review with case studies. London: Chartered Institute of Management Accountants.

48. Snead, M. (2012). Modular production - a new concept. Harvard Business Review, 43(6):131-142.

49. Spoede, C. Henke, E. \&Umble, M. (2014). Using activity analysis to locate profitability drivers: ABC can support a theory of constraints management process. Management Accounting 75 (11):25-26.

50. Theeuwes, U. \&Adriaansen, M. (2014). Optimal commonality in component design. Operations Research, 48(1):1-19.

51. Turner, P. B. (2013). Activity based costing - The performance breakthrough. London: Kogan Page Limited.

52. Yamane, T. (1984).Products and modularity. Research Centre, Helsinki University of Technology. 